\title{
Research on Psychological Capital Intervention of College Students
}

\author{
Shufen Li, Hongying Li \\ College of Yatai business administration \\ Jilin University of Finance and Economics \\ Changchun, China \\ 157199637@qq.com
}

\author{
Chichao Xu \\ Finance Office \\ Jilin University of Finance and Economics \\ Changchun, China \\ 2571351981@qq.com
}

\begin{abstract}
Improving college students' psychological capital can effectively enhance their employability. In the paper, the students from Jilin University of Finance and Economics were taken as samples to look into the current situation and influencing factors of psychological capital of college students by the questionnaire survey. The research finds that the differences in disciplines have the greatest impact on the overall level, and the differences between the source place and gender of the students have little effect on the overall level of the students' psychological capital, which are mainly reflected in the fluctuation of the differences among the dimensions. Aiming at the problems existing in the psychological capital of college students, the proper positive intervention measures are proposed in the paper from the external environment optimization intervention and internal model intervention.
\end{abstract}

Keywords-Psychological capital; Hope; Self-efficacy; Optimism; Tenacity; Model intervention

\section{INTRODUCTION}

"Psychological Capital" is gradually derived from the influence of positive psychological thoughts in the United States. In 2002, the American psychologist Seligman first proposed the concept of "Psychological Capital", and attributed the psychological factors that lead individuals to produce positive behaviors to "Psychological Capital". In 2004, on the basis of this concept, Professor Luthans of University of Nebraska redefined the psychological capital as a positive psychological state that is gradually formed and reflected by the individual in the growth and development process combined with the relevant theories of active organizational psychology and active organizational psychology from the new angle of view. It mainly reflected in four aspects of hope, selfefficacy (self-confidence), optimism and tenacity, and the concept of "Psychological Capital" was formally formed [1].

As the main fostering base for national talents, the colleges and universities are the primary channels for the organization of human resources, and undertake the important mission of

Jilin Social Science Fund Project: Study on HRM Innovation in Service Enterprise in Jilin Province-Based on Psychological Capital Perspective(Project No. 2017B75). Jilin Social Science Project: Study on HRM Problems and Countermeasures of New Enterprise in Service Sector in Jilin Province(Project No. 2018JD30). Education Department in Jilin Province "the Twelfth Five Plan" Social Scientific Research: Study on Talent Support System for the Development of Culture Industry in Jilin Province(Project No.: 2014P159). Project of Jilin University of Finance and Economics: Study on HRM Innovation in Service Enterprise Based on Psychological Capital(Project No.: 2016P44). training high talents. Some research work has showed that the university students' psychological capital is closely related to the employment ability. Through the positive intervention of university students' psychological capital, improvement of their psychological environment and promotion of their social value, it will be helpful to promote the improvement of students' employment ability.

\section{Psychological CAPITAl Structure of University STUDENTS}

According to the definition of psychological capital from Luthans[2], the structure of psychological capital is divided into four dimensions: hope, optimism, self-efficacy (selfconfidence) and tenacity, which is defined from these four dimensions in this research.

Hope refers to the purposeful and methodical planning approach when the students complete a designated task, a positive mental attitude that adjusts the completion path timely until the goal is reached according to the corresponding environmental factors, and a reflection of positive energy, which has strong infection.

Self-efficacy refers to the subjective prediction of selfability, possibility of completion and degree of completion when the university students complete a designated task. Popular speaking, it refers to the degree of individual selfconfidence.

Optimism refers to the positive expectations of university students toward things to come, and a positive psychological state that the university students attribute the advantages of things what happened to the subjective and the disadvantage as the objective.

Tenacity refers to the self-regulation ability to quickly restore its physical and psychological quality to the state before setbacks when it undergoes major changes, setbacks and crises. Tenacity often reflects the individual's stress tolerance and psychological barriers from the side as well as the efficiency of responding to problems and restoring survival. 


\section{INVESTIGATION ON CURRENT Situation OF} Psychological Capital of University STUdents

\section{A. Investigation Process}

In order to understand the current situation of psychological capital of university students, the method of convenience sampling is used to investigate and survey the students from Jilin University of Finance and Economics in this research from March to April 2018 through the questionnaire survey. The questionnaire uses the psychological capital questionnaire written by Associate Professor Zhang Kuo[3].The questionnaire uses 26 questions to measure self-efficacy, tenacity, hope, and optimism, which has been widely used in domestic academia with higher reliability and reliability. The scoring method uses Likert summated rating scale for scoring respectively from full compliance to complete nonconformance. The scores of each dimension are averaged. The higher the score is, the better the psychological capital situation will be. The investigation and survey is completed through onsite distribution and so jump. A total of 408 questionnaires were withdrawn. 340 valid questionnaires were retained, and the effective recovery rate was $83 \%$ after excluding questionnaires that were filled out with too short time, presented an obvious regularity answer, and filled out missing items.

\section{B. Investigation and Statistics}

Through the basic information classification of part one and psychological capital level of part two, the statistical data is measured in the questionnaire as shown in table 1 , where the sample counting $n=340$. From the perspective of grade, there is a big gap in the results of psychological capital research of university students, and the situation in which psychological capital level of freshman is lower than that of other grades is more obvious. The reason for this may be that freshmen are in the state of ignorance and adaptation for university life, and still confused about most of their lives. Coupled with the fact that most freshmen are going to school for the first time at a distance from home with high psychological pressure, which leads to a lower level of psychological capital.

From the perspective of the place and gender of student, there is little difference in the level of psychological capital. However, the psychological capital of disciplines and outstanding students is quite different. It will be analyzed by category as follows.

It can be seen that the level of psychological capital is significantly lower than other three indexes from the dimension of optimistic psychological capital, but the freshman's tenacity indexes are relatively high. In terms of the source of this demography factor, the difference of psychological capital among university students under the source place is small. Gender differences between men and women are not obvious in the overall level of psychological capital among students, but show a certain degree of difference in the four dimensions. The optimism and self-efficacy of male university students is significantly higher than that of female university students, and the tenacity and desired value of female university students are higher than that of male higher than that of male university students. To sum up, there is no difference in the overall level of gender representation. Women are less optimistic and less confident than men. Males are less resilient and hopeful than women, which do not affect the overall performance of psychological capital level.

The level of psychological capital of university students is significantly affected by outstanding students. Outstanding students here refer to party members, student cadres, and university students who have won scholarships. The students who have one of the above behaviors are listed as outstanding students. The psychological capital level of outstanding students is higher than that of non-outstanding students in four dimensions. The differences in the level of psychological capital of university students have a bigger influence from the perspective of discipline. The students of liberal arts are generally in a disadvantageous position in the four dimensions of psychological capital compared with students of science.

TABLE I. MEASUREMENT AND ST ATISTICS OF PSYCHOLOGICAL CAPIT AL LEVEL (N=340)

\begin{tabular}{|c|c|c|c|c|c|c|c|}
\hline \multicolumn{8}{|c|}{ Statistics of psychological capital level of students of Jilin University of Finance and Economics } \\
\hline Category & Dimension & $\begin{array}{l}\text { Number } \\
\text { of people }\end{array}$ & $\begin{array}{c}\text { Average of } \\
\text { desired } \\
\text { value }\end{array}$ & $\begin{array}{c}\text { Average of } \\
\text { optimistic } \\
\text { value }\end{array}$ & $\begin{array}{c}\text { Average of } \\
\text { self-efficacy } \\
\text { value }\end{array}$ & $\begin{array}{c}\text { Average of } \\
\text { tenacity } \\
\text { value }\end{array}$ & $\begin{array}{c}\text { Level of } \\
\text { psychological } \\
\text { capital }\end{array}$ \\
\hline \multirow{2}{*}{ Grade } & Sophomore & 44 & 4.3 & 4 & 4.6 & 4.4 & 4.33 \\
\hline & Junior & 156 & 4.1 & 3.7 & 4.6 & 4.3 & 4.18 \\
\hline $\begin{array}{c}\text { Origin of } \\
\text { student }\end{array}$ & Rural area & 212 & 4.15 & 3.9 & 4.1 & 4.5 & 4.16 \\
\hline \multirow{2}{*}{ Gender } & Male & 155 & 3.8 & 4.7 & 4 & 3.9 & 4.10 \\
\hline & Female & 185 & 4.2 & 4.1 & 3.75 & 4.5 & 4.14 \\
\hline \multirow{2}{*}{$\begin{array}{c}\text { Outstanding } \\
\text { student }\end{array}$} & Yes & 131 & 4.2 & 4.5 & 4.7 & 4.6 & 4.50 \\
\hline & No & 209 & 3.9 & 3.7 & 4.1 & 4 & 3.93 \\
\hline
\end{tabular}




\section{Measures for Psychological Capital INTERVENTION OF UNIVERSITY STUDENTS}

\section{A. External Environmental Intervention}

First of all, pay more attention to the status of psychological capital of university students in the government level, introduce and encourage the related policy of psychological capital construction activities, timely organize the activity that is beneficial to psychological capital construction of university students, and create a comprehensive, fair and competitive employment environment for university students; secondly, pay closely attention to the psychological capital construction of university students, help university students establish a correct employment concept and practicing attitude, actively and optimistically meet the challenges, and improve the desired value of university students so as to enhance the psychological capital level of university students.

The employing unit should strengthen the supervision dynamics over the fairness of recruitment process, expand the scope of recruitment, and provide more employment opportunities fair platform for university students. The internship units should pay more attention to the psychological capital status of university students in the internship process, and timely communicate with the academic institution. The school journal and media shall publish and report more positive employment incentive policies, success science representative as well as academic and social practice and other related suggestions; train the students' positive energy, reduce academic pressure and employment pressure so as to improve the university students' self-efficiency and optimism index and the overall level of psychological capital.

The school organization should actively carry out psychological capital education courses and expert lectures by taking class as a unit, pay attention to the healthy development of psychological capital of the students, strengthen the active teaching atmosphere in the school, regularly organize cultural and sports activities and call for students for participation, and promote the sense of ownership of the university students so as to enhance their self-efficacy. In terms of employment, through a complete employment service system, provide the university students with positive, active and targeted employment guidance; reduce university students' employment pressure and promote the diversified development of employment direction of university students to avoid blind conformity and selfcontemptuous subnormal state of mentality.

\section{B. Model Intervention}

The experimental verification of psychological capital intervention model of Lutans: Psychological capital can be distinguished by model intervention, namely our dimensions within the model, and the corresponding simulation situation is designed. The inertial thinking mode is formed to improve the comprehensive level of psychological capital through repeated training. Based on psychological capital intervention model of Lutans, the author designs the applicable development behavioral pattern for university students by taking university students as objection angle in order to have a positive impact on psychological capital through special development of internal model factors. The model is designed as follows:

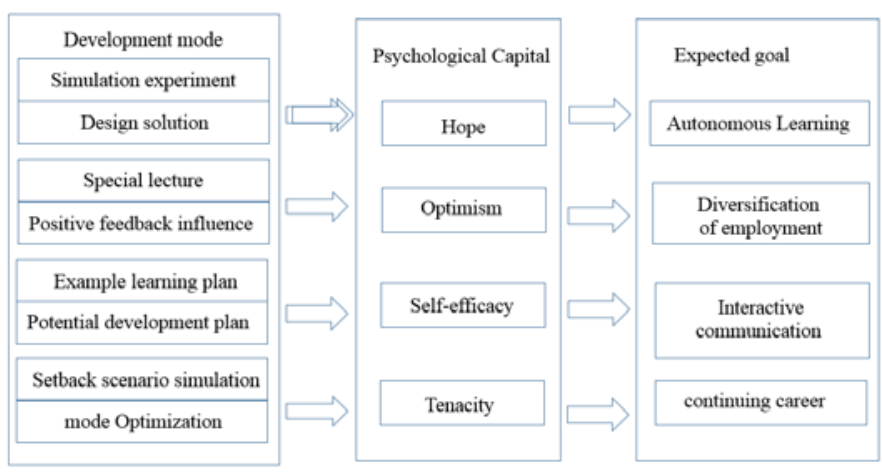

Fig. 1. Psychological capital intervention models of university students

\section{1) Hope Intervention}

Hope refers to a positive state reflected by individual the process of behavior. The individuals who are full of hope can actively cope with difficulties in the course of behavior, and have clear goals and goal decomposition capabilities. The implementation of positive hope intervention for university students is the primary subject for university educators to intervene in psychological capital level of university students [4].

In this model, the implementation of hope intervention for university students is to design simulated target experiments, develop experimental sandbox courses, complete certain goals in a group-team collaborative manner, and exercise students' target decomposition ability in the process of completing goals. The group is taken as the unit to design the problem solving plan. Through the repeated experiment simulation and process of decomposing different goals, the students are trained to build the hope, set multiple solutions in the face of different goals, anticipate the difficulties that may encounter, make a good plan for solving the expected difficulties, and form an inertial way of doing a good job beforehand to improve the desired value of students.

\section{2) Optimistic Interventin}

Optimism is the biased performance of psychological expectation when an individual faces the difficulty, which is opposite to pessimism. The optimistic individuals tend to expect results in a positive direction. Their tolerance, comprehension, adaptability and ability to change the influence of environment on groups are high. The implementation of positive optimistic intervention on students can not only improve the level of individual psychological capital, but also produce group effect. Individuals in the group show the optimism level that can effectively improve the optimistic level of the individuals, namely organization influence effect.

In this model, the way to implement optimistic interference for university students is to hold periodical thematic analysis lectures. The topics can be designed in the domain of employment situation analysis, mental health education, and dialectical thinking theory for the purpose of educating students to learn to think in many ways. When the students can objectively analyze problems and situations and dialectically view the good and bad results, they can treat everything in the 
inclusive attitude and open eyes, and tend to be optimistic for the expectations of results. When the results are not as expected, they can conduct dialectical analysis. Afflictions are sometimes blessings in disguise. The overall optimistic index of organization can be effectively promoted by always maintaining the expectation of the future and optimistic positive energy for infection of the groups, and enhancing the positive energy feedback among students.

\section{3) Self-efficacy Intervention}

The development of self-efficacy is also the process of selfunderstanding biased towards positive optimism. The individuals with higher self-efficacy have decisive behaviors, clear and persistent target as well as continuous effort.

The way to implement the self-efficacy interventions for university students is to enable students to fully recognize the development dimensions of their potential through the establishment of goal models and the awakening of selfknowledge, and continuously draw advantages from the target model through the learning plan. Each student chooses a target model, analyzes the target advantages and designs the schedule of study plan. At the same time, the teacher helps students analyze their own advantages and potential to be developed, and conducts the phased assessments of the learning plan so that the students can fully recognize their advantages to achieve a phased improvement in terms of deficiencies through example target learning. The students' self-efficacy can be significantly enhanced.

\section{4) Tenacity Intervention}

The tenacity dimension of university students is mainly reflected in the ability to overcome obstacles in the completion process of learning objectives, the ability to recover from job hunting, and the regulating ability in the face of difficulties in life. The individuals with strong resilience will actively respond to such difficulties, and quickly adjustment themselves to fit in the environment. They are challenging in the face of adversity, good at challenging difficulties and breaking through themselves.

In this model, the way to implement the tenacity intervention for university students is to design the scenario simulation course, which can be combined with the sandbox simulation of hope intervention. The task object is set in groups, and multiple obstacles are set in the course of goal completion. The obstacle overcoming training is carried out by taking the group as the unit. When the goal is not completed, the counselor assists the student to adjust themselves and guide psychological health counseling. On the one hand, the students' adversity growth ability can be exercised. On the other hand, their self-regulatory ability can be trained so as positively influence the resilience on the university.

\section{CONCLUSION}

In this study, the students from Jilin University of Finance and Economics are taken as the sample to understand the students' current psychological capital level through the questionnaire survey, analyze the main reasons for the differences, and design active intervention measures for psychological capital of university students from the aspects of external environment intervention and internal model technical intervention. The research conclusions are summarized as follows:

The overall level of psychological capital of students form Jilin University of Finance and Economics is in the normal state. There are fluctuations in each dimension index, but the overall level remains stable. As the access to social talents, the colleges and universities effectively promote the construction of university students' psychological capital, which can not only achieve individual value-added but also reduce the organization's human cost, and achieve high-performance output of the organization.

The reasons for the difference in level of psychological capital generated are mainly discipline differences, grade differences, outstanding student differences, student source differences, and gender differences. Among them, the discipline differences have little influence on overall level of the students' psychological capital, and the main impact is reflected in the differences and fluctuations among the various dimensions.

The positive influence intervention on the psychological capital level of university students starts from two aspects: One is the optimization of external environment, and the other is the design of corresponding simulation experiment courses for four dimensions. The inertial thinking is formed through repeated training so as to enhance the overall level of university students' psychological capital.

\section{REFERENCES}

[1] F Luthans, CM Youssef, "Human, Social, and Now Positive Psychological Capital Management: Investing in people for competitive advantage,” Organizational Dynamics, vol.33, pp. 143-160, February 2004.

[2] KW Luthans, SM Jensen, "The linkage between psychological capital and commitment to organizational mission: a study of nurses," Journal of Nursing Administration, vol.35, pp. 304, June 2005.

[3] Kuo Zhang, Sai Zhang and Yinghong Dong, "Positive Psychological Capital: Relationship between Measurement and Its Mental Health," Studies of Psychology and Behavior Research, pp. 58-64, January 2010.

[4] Yuanyuan Zhou, "Research on the development strategy of College Students' psychological capital from the perspective of entrepreneurship education practice," Heilongjiang Researches on Higher Education, pp.111-113, October 2016. 